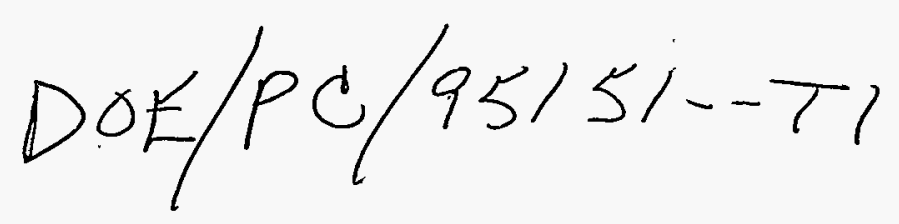

TECHNICAL PROGRESSS REPORT

\author{
for the Second Quarter \\ (January 1, 1996 to March 31, 1996) \\ RECERE? \\ JUL 18 mis \\ 오요

\section{POC-SCALE TESTING OF A DRY TRIBOELECTROSTATIC SEPARATOR FOR FINE COAL CLEANING} \\ by \\ R.-H. Yoon, G.H. Luttrell, and G.T. Adel \\ Center for Coal and Minerals Processing \\ Virginia Polytechnic Institute \& State University \\ Blacksburg, Virginia 24061-0258
}

Grant Number:

DE-AC22-95PC95151

Project Manager:

Dr. Michael Nowak

U.S. Department of Energy

Pittsburgh Energy Technology Center

P.O. Box 10940

Pittsburgh, Pennsylvania 15236

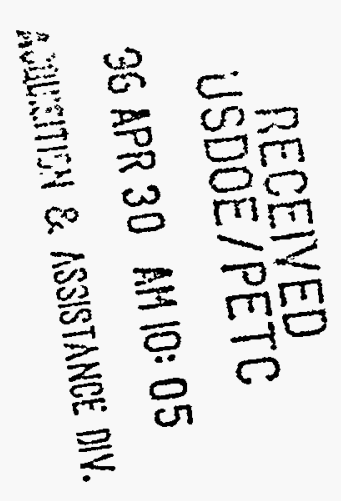

MASTER

U.S./DOE Patent Clearance is not required prior to the publication of this document. 


\section{DISCLAIMER}

Portions of this document may be illegible in electronic image products. Images are produced from the best available original document. 


\begin{abstract}
The Pittsburgh Energy Technology Center (PETC) developed a triboelectrostatic separation (TES) process which is capable of removing mineral matter from coal without using water. A distinct advantage of this dry coal cleaning process is that it does not entail costly steps of dewatering which is a common problem associated with conventional fine coal cleaning processes. It is the objective of this project to conduct a series of proof-of-concept (POC) scale tests at a throughput of $200-250 \mathrm{~kg} / \mathrm{hr}$ and obtain scale-up information. Prior to the POC testing, benchscale test work will be conducted with the objective of increasing the separation efficiency and throughput, for which changes in the basic designs for the charger and the separator may be necessary. The bench- and POC-scale test work will be carried out to evaluate various operating parameters and establish a reliable scale-up procedure. The scale-up data will be used to analyze the economic merits of the TES process.

All required documents associated with project planning were completed and submitted to DOE for approval during the second quarter of this project. Approval of the project work plan is still pending at this time subject to addition review by DOE of requested modifications to the statement of work. Accomplishments during this reporting period include the set-up of an apparatus for assessing tribocharger performance, continued construction of the bench-scale (1 $\mathrm{kg} / \mathrm{hr}$ ) triboelectrostatic separator and initial development of a fundamental model for predicting the motion of charged particles in a non-uniform electrostatic field.
\end{abstract}




\section{TABLE OF CONTENTS}

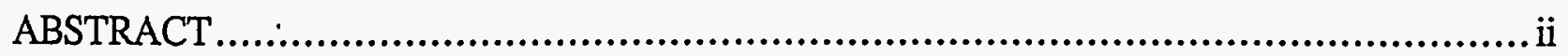

TABLE OF CONTENTS ...................................................................... iii

LIST OF FIGURES....................................................................... iv

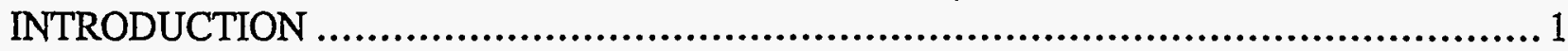

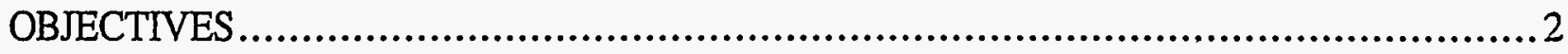

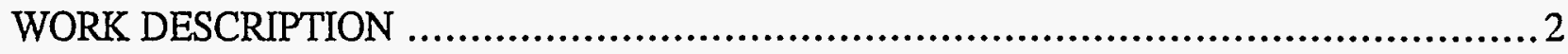

Task 1 - Project Planning ............................................................... 2

Task 2 - Sample Acquisition .............................................................2

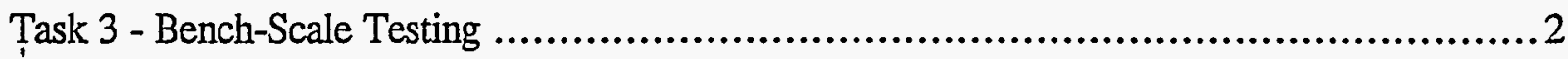

Subtask 3.1 - Charger Testing ........................................................... 3

Subtask 3.2 - Separator Testing ........................................................ 5

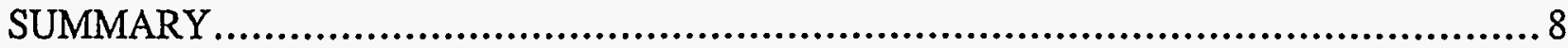

\section{DISCLAIMER}

This report was prepared as an account of work sponsored by an agency of the United States Government. Neither the United States Government nor any agency thereof, nor any of their employees, makes any warranty, express or implied, or assumes any legal liability or responsibility for the accuracy, completeness, or usefulness of any information, apparatus, product, or process disclosed, or represents that its use would not infringe privately owned rights. Reference herein to any specific commercial product, process, or service by trade name, trademark, manufacturer, or otherwise does not necessarily constitute or imply its endorsement, recommendation, or favoring by the United States Government or any agency thereof. The views and opinions of authors expressed herein do not necessarily state or reflect those of the United States Government or any agency thereof. 


\section{LIST OF FIGURES}

Figure 1. Schematic of the set-up for evaluating tribocharger performance.....................9

Figure 2. Schematic of the "open-flow" Faraday cage .......................................10

Figure 3. Schematic of the "bag-filter" Faraday cage .........................................11

Figure 4. Side-view of the bench-scale electrostatic separator ............................... 11 


\section{INTRODUCTION}

Numerous advanced coal cleaning processes have been developed in recent years that are capable of substantially reducing both ash- and sulfur-forming minerals from coal. However, most of the processes involve fine grinding and use water as cleaning medium; therefore, the clean coal products must be dewatered before they can be transported and burned. Unfortunately, dewatering fine coal is costly, which makes it difficult to deploy advanced coal cleaning processes for commercial application.

As a means of avoiding problems associated with the fine coal dewatering, the Pittsburgh Energy Technology Center (PETC) developed a dry coal cleaning process, in which mineral matter is separated from coal without using water. In this process, pulverized coal is subjected to triboelectrification before being placed in an electric field for electrostatic separation. The triboelectrification is accomplished by passing a pulverized coal through an in-line mixer which is made of copper, whose work function lies in-between those of carbonaceous material (coal) and mineral matter. Thus, coal particles impinging on the copper wall loses electrons to the metal, thereby acquiring positive charges, while mineral matter impinging on the wall gains electrons to acquire negative charges. The triboelectrostatic separation (TES) ${ }^{-}$process has been tested successfully on bench-scale. The results obtained at PETC showed that is capable of removing more than $90 \%$ of the pyritic sulfur and $70 \%$ of the ash-forming minerals from a number of eastern U.S. coals. It is necessary, however, to test the process on a proof-of-concept scale so that appropriate scale-up information is obtained. Furthermore, it is necessary to increase the throughput of the TES process by improving the design for the electrostatic separation system. 


\section{OBJECTIVES}

It is the objective of the project to further develop the triboelectrostatic separation (TES) process developed at the Pittsburgh Energy Technology Center (PETC) through bench- and proof-ofconcept scale test programs. The bench-scale test program is aimed at studying the charging mechanisms associated with coal and mineral matter and improving the triboelectrification process, while the POC-scale test program is aimed at obtaining scale-up information. The POC-scale tests will be conducted at a throughput of $200-250 \mathrm{~kg} / \mathrm{hr}$. It is also the objective of the project to conduct cost analysis based on the scale-up information obtained in the present work.

Specific objectives of the work conducted during the first quarter were: i) to complete projẹct planning, ii) to procure necessary coal samples, iii) to design an apparatus for studying triboelectrification mechanism with an objective of maximizing separation efficiency, and iv) to design an efficient electrode system to maximize throughput.

\section{WORK DESCRIPTION}

\section{Task 1: Project Planning}

The draft project work plan was prepared and submitted to the DOE for review. This document provided a detailed description of the test programs, experimental procedures, analytical methods, and reporting guidelines that would be utilized in the successful completion of the proposed work. The draft project work plan was modified from the original statement of work to reflect new technical information gathered by the contractor since the original project award. These modifications are presently being discussed with the project $\mathrm{COR}$. 
Drafts of several other technical/management project plans have also been submitted to DOE for review and comment. These included the management plan, milestone schedule/plan, reporting schedule/plan, labor plan, cost plan, and hazardous substance plan. Final approval of these documents by DOE is pending at this time.

\section{Task 2: Sample Acquisition}

As stated in the previous quarterly report, a sample of Pittsburgh No. 8 seam coal was chosen for the initial bench-scale test work. One 55 gallon drum of this sample was delivered to the Plantation Road Coal Testing Facility at Virginia Tech on January 25, 1996. To minimize problems associated with sample oxidation/deterioration, the remaining two coal samples (i.e., Elkhorn No. 3 and Wyodak) will be delivered after completing the bench-scale test work with the Pittsburgh coal.

\section{Task 3 - Bench-Scale Testing}

\section{Subtask 3.1 - Charger Tests}

During the past quarter, an apparatus was constructed for evaluating the charging efficiency of various in-line static mixer tribochargers. A schematic drawing of the test apparatus is shown in Figure 1. At present, this equipment is being used to determine the effects of tribocharger geometry and gas flow velocity on charging performance. The effects of mixer geometry will be investigated by conducting tests using standard $2.22-\mathrm{mm}(0.875$-inch) diameter mixers with lengths of $15.2,22.9$ and $30.5 \mathrm{~mm}(6,9$ and 12 inches). In each test, the superficial gas velocities are being monitored using a standard rotometer over a range of flow rates from 0.4 to $4.0 \mathrm{~m} / \mathrm{sec}$. After completing these tests, additional experiments will be conducted using inline static mixers constructed from various types of materials (e.g., copper, stainless steel and 
PVC) so that the influence of material type on charging performance can be established.

The test system developed in the present work has been equipped with a Faraday cage for measuring the surface charge of particles pneumatically transported through the in-line static mixer tribocharger. The Faraday cage, which is shown in Figure 2, consists of matched sets of inner and outer copper cylinders electrically isolated using nonconductive Teflon spacers. The cage was designed and built in a cylinder shape in order to minimize problems associated with charge leakage. During testing, a slipstream of charged particles from the static mixer is diverted into a sample collection cup mounted inside the inner cylinder. The cup is constructed from copper so that the particles indirectly charge the inner cylinder by induction. The magnitude of the charge is monitored using a Keithly Model-642 electrometer which is connected to the inner cylinder by a shielded copper wire. The outermost cylinder is grounded to prevent the charge measurement device from being influenced by stray electric fields. To prevent particles from blowing out of the sample collection cup, the bottom of the cup is covered with a fine (200 mesh) copper sieve which retains the particles and allows the gas to pass out the bottom. The system has been designed so that the sample cup can be removed for sample collection and the innermost cylinder can be taken off for cleaning and inspection. Test results obtained with this system will be summarized in the next technical project report.

The charge measurement system described above cannot be used with particles finer than approximately 75 microns since they would pass through the 200 mesh sieve in bottom of the sample collection cup. Therefore, a second design for the Faraday cage has been developed as shown in Figure 3. This system is also constructed of copper and the inner cylinder is connected to the Keithley Model-642 electrometer. However, in this case, a bag 
filter has been placed inside the inner cylinder to collect the charged particles. The bag will not affect the charge measurement since it is a nonconductive material. This equipment will be used to measure particle charge as a function of sample collection time. The average charge per unit mass will be determined by integrating the area under the resultant time-charge curve and dividing by the total mass of the particles collected in the filter bag.

\section{Subtask 3.2-Separator Tests}

\section{a) Separator Construction}

Tasks associated with the fabrication and set-up of the bench-scale triboelectrostatic separator were continued during the past quarter (see Figure 4). During the construction of the separator, problems were encountered in finding the proper materials for fabricating the electrodes and electrode supports. In determining the material for the electrodes, a number of factors were considered including charging behavior, wear-resistance and fabrication suitability (i.e., ease in constructing drums of thin sheets of the material). Based on these factors, it was decided that the electrodes should be constructed from brass. Teflon was selected as the most appropriate material for holding the electrodes in position because of the low electrical conductivity, high strength and excellent heat resistance of Teflon.

Power packs for the bench-scale separator were also procured and shipped to the test facility during the past quarter. The power packs are capable of attaining a maximum applied voltage across the electrodes of $100 \mathrm{kV}$ (i.e:, $+50 \mathrm{kV}$ applied to the positively charged electrode and $-50 \mathrm{kV}$ applied to the negatively charged electrode). This field strength is considered to be sufficient for the small size of the particles that will passed through the separator. 
The design and construction of dust handling systems was also initiated during the past quarter. At present, the fine particulate product streams from the bench-scale separator will be collected in individual bag-house chambers (one for clean coal and the other for refuse) which were specially constructed for this project. The bag-house chamber will be equipped with a variable-speed blower motor so that the vacuum intensity and air flow rates through each chamber can be accurately controlled. Current studies indicate that a velocity in the range of 1 to $4 \mathrm{~m} / \mathrm{s}$ would be ideal for the flow velocity of particles through the separator.

\section{b) Separator Modeling}

In accordance with the project work plan, tasks were also initiated during the past quarter to begin the development a mathematical model which describes the behavior of the bench-scale triboelectrostatic separator. Because of the cylindrical electrode design, the benchscale unit produces a non-uniform electrostatic field which is substantially different from the uniform fields generated by previous designs which utilized flat-plate electrodes. The nonuniform field induces an additional force on the particles that varies from the top to bottom of the electrodes. At present, the model is being used to investigate the motion of charged particles in the non-uniform electrostatic field. Eventually, the model will be used to study the impact of changes in electrical potential and drum diameter on separator performance.

The present form of the model assumes that the applied force on a particle is determined by the net charge on the particle and the acting electrostatic field strength, i.e.:

$$
F_{1}=q E
$$

where $F_{1}$ is the electrostatic force of attraction (or repulsion), $q$ is the charge induced on the particle and $E$ is the electric field strength acting between the electrodes. This expression is 
valid for conventional electrostatic separators which use flat-plate electrodes. In this case, there is a uniform electric field acting between the electrodes along the whole length of the plates. As a result, the only force acting on the particles is that due to the charges on the particle surfaces.

The separator design developed at CCMP utilizes drum-shaped electrodes which create a non-uniform electrostatic field which varies from the top to bottom of the electrodes when viewed from the side. In this case, an additional force must be considered play due to the spatial variations in the electric field (or the gradient of the electric field). This additional force is given by:

$$
F_{2}=K \operatorname{grad}(E)
$$

where $\operatorname{grade}(E)$ describes the electrical field gradient and $K$ is a constant derived from experimental measurements. Therefore, the total force acting on particles passing through a non-uniform electrostatic field is obtained by the summation of $F_{1}$ and $F_{2}$, i.e.:

$$
\begin{aligned}
F & =F_{1}+F_{2} \\
& =q E+\operatorname{Kgrad}(E)
\end{aligned}
$$

Preliminary calculations indicate that the latter force tends to be dominant for the case of cylindrical electrodes. Although preliminary calculations to determine the optimum values for these parameters have been performed, details associated with these calculations and a complete description of the model will not be provided until the next quarterly report. 


\section{SUMMARY}

During the second quarter of this project, all required documents associated with project planning were completed and submitted to DOE for approval. Approval of the project work plan is still pending at this time. Accomplishments achieved during the current reporting period include i) set-up of an experimental apparatus for evaluating the performance of the various in-line mixer tribochargers, ii) continued fabrication and construction of the bench-scale $(1 \mathrm{~kg} / \mathrm{hr})$ electrostatic separator and iii) preliminary development of a mathematical model for describing the behavior of charged particles in a non-uniform electrostatic field. 

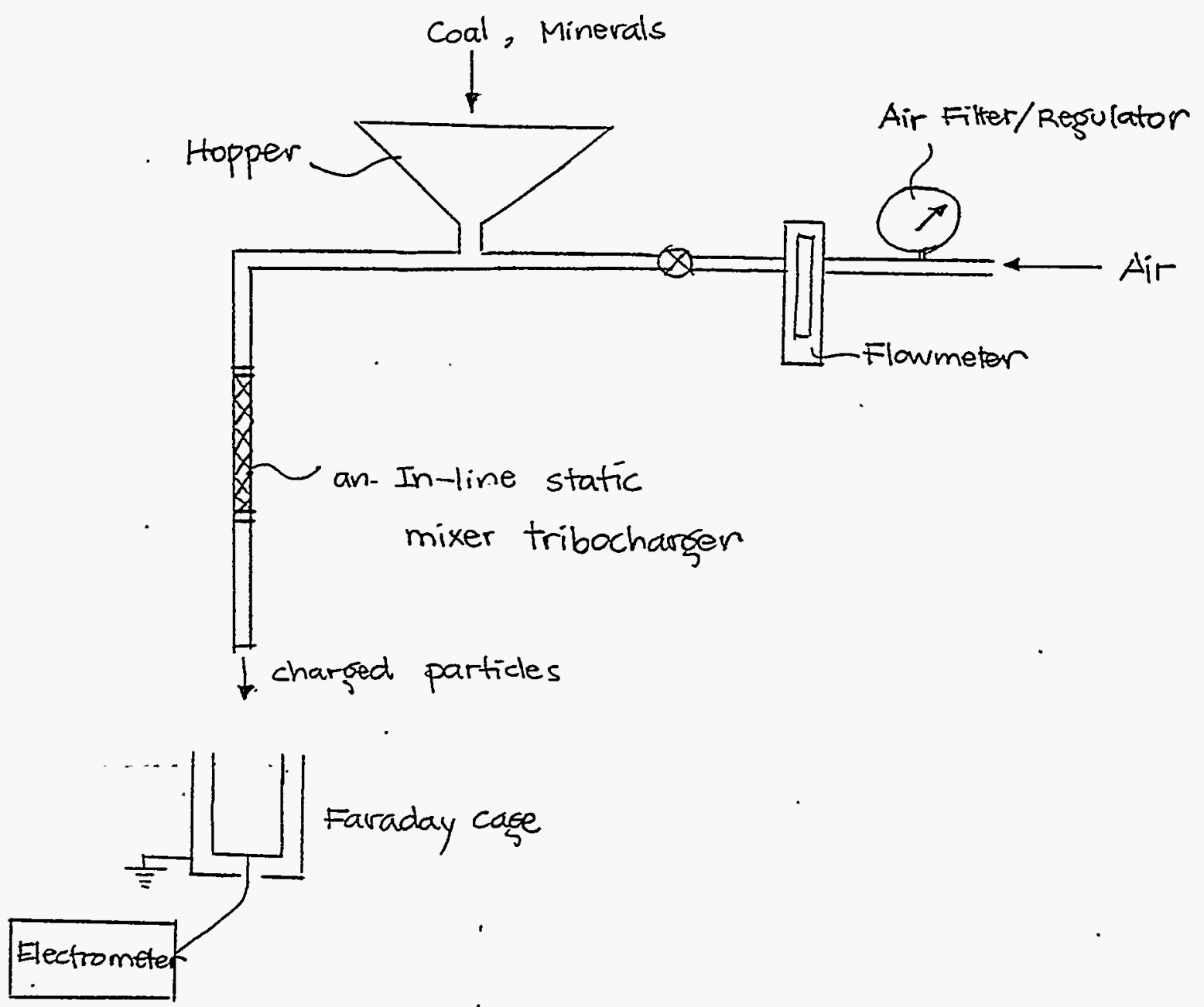

fig. 1 Schematic View of Experimental Setup. 


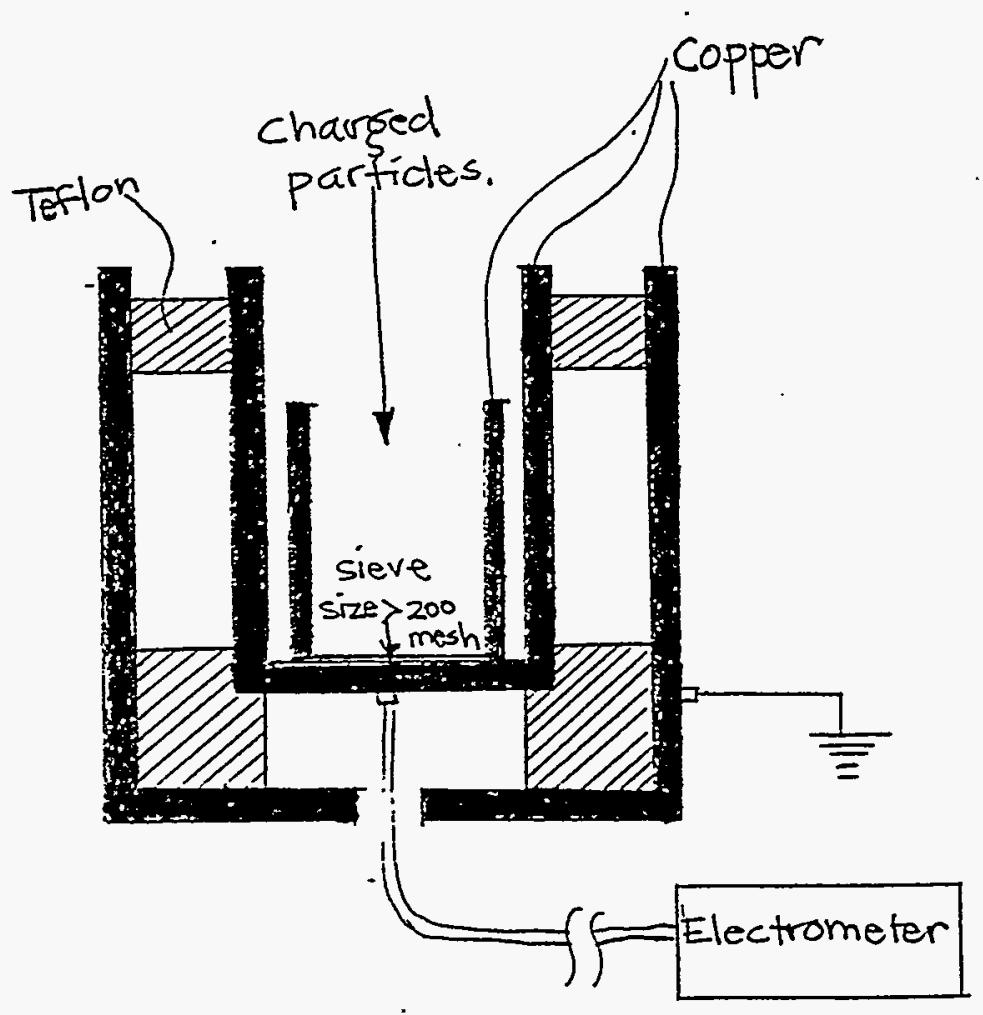

Fig. 2 A cylinder-shape Faraday cage \#i. 


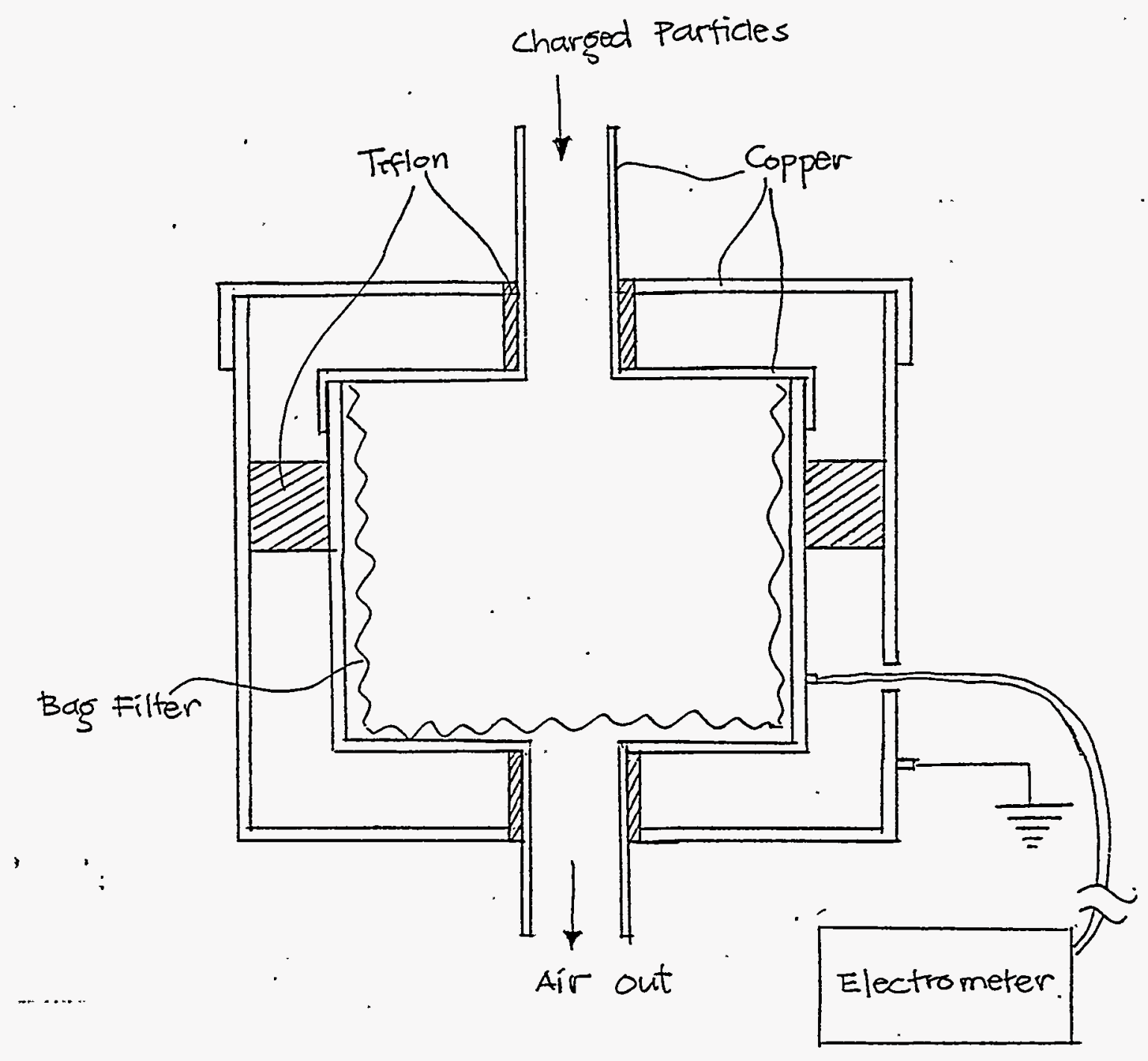

Fig.3 A cylinder-shape Faraday cage. \#2 with a bag filter, 


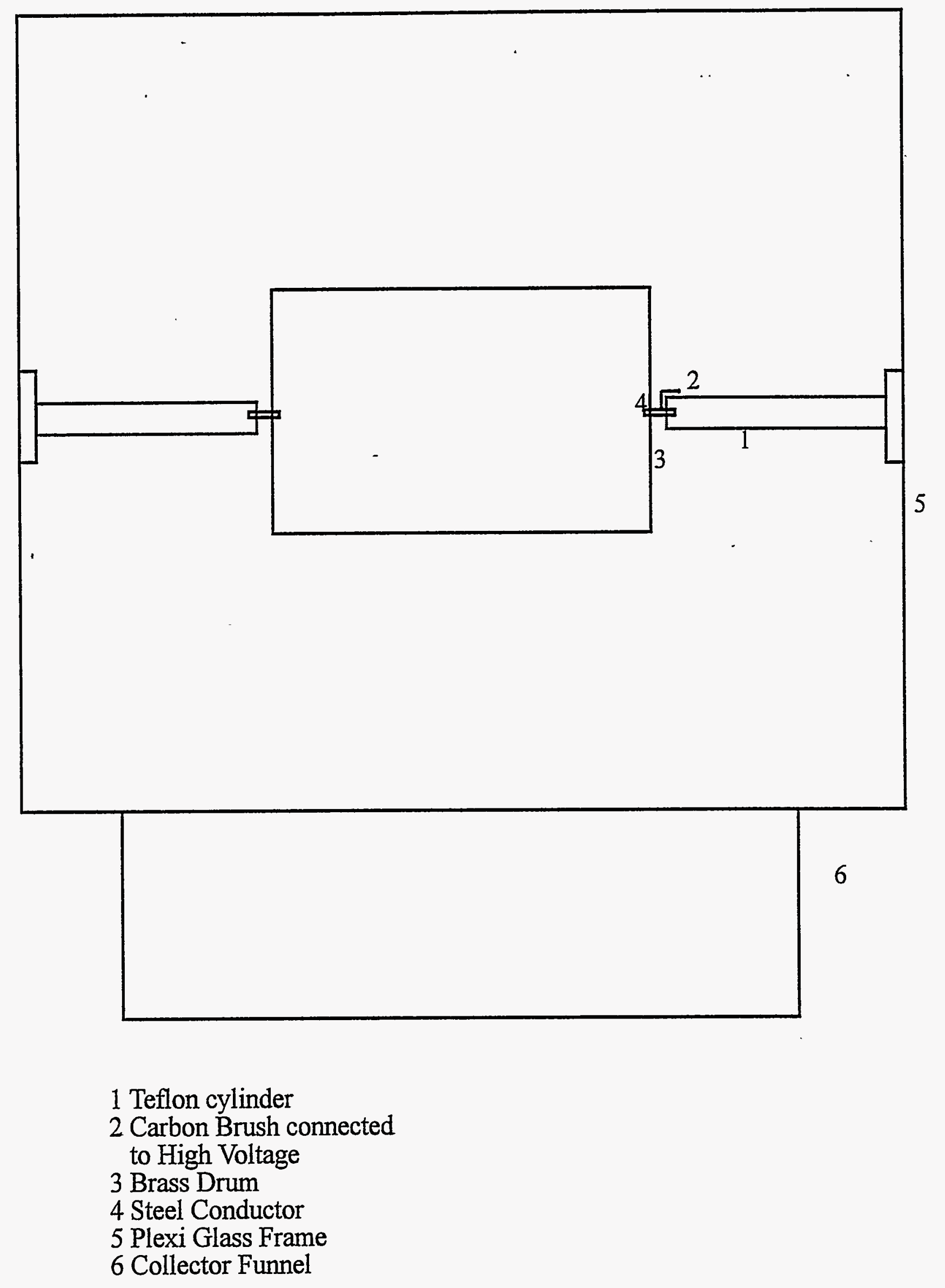

